\title{
Risk-Based Estimate of Human Fungal Disease Burden, China
}

Ling-Hong Zhou, ${ }^{1}$ Ying-Kui Jiang, ${ }^{1}$ Ruo-Yu Li, Li-Ping Huang, Ching-Wan Yip, David W. Denning, ${ }^{2}$ Li-Ping Zhu ${ }^{2}$

We conducted a systematic literature review to obtain risk population-based fungal disease incidence or prevalence data from China. Data were categorized by risk factors and extrapolated by using most recent demographic figures. A total of $71,316,101$ cases ( $5.0 \%$ of the population) were attributed to 12 risk factors and 17 fungal diseases. Excluding recurrent Candida vaginitis $(4,057 / 100,000$ women) and onychomycosis (2,600/100,000 persons), aspergillosis $(317 / 100,000$ persons) was the most common problem; prevalence exceeded that in most other countries. Cryptococcal meningitis, an opportunistic infection, occurs in immunocompetent persons almost twice as often as AIDS. The pattern of fungal infections also varies geographically; Talaromyces marneffei is distributed mainly in the Pearl River Basin, and the Yangtze River bears the greatest histoplasmosis burden. New host populations, new endemic patterns, and high fungal burdens in China, which caused a huge impact on public health, underscore the urgent need for building diagnostic and therapeutic capacity.

$\mathrm{F}$ ungal diseases constitute a growing problem worldwide, causing a large, but poorly quantified, impact on public health (1). The incidence of fungal infections varies according to geographic region, socioeconomic conditions, and the number of persons with underlying conditions. China is one of the largest countries in the world (largest population and third largest land area). It has almost every type of weather niche, from the Pacific coast in the south to the snowy mountains in the Qinghai-Tibet Plateau, and even tropical rain forest. Many endemic fungal infections are present in China, along with globally distributed fungal

Author affiliations: Huashan Hospital, Shanghai, China; and Fudan University, Shanghai (L.-H. Zhou, Y.-K. Jiang, L.-P. Huang, C.-W. Yip, L.-P. Zhu); Peking University First Hospital, Beijing, China (R.-Y. Li); Peking University, Beijing (R.-Y. Li); National Clinical Research Center for Skin and Immune Diseases, Beijing (R.-Y. Li); Wythenshawe Hospital, Manchester, UK (D.W. Denning); University of Manchester, Manchester (D.W. Denning); Global Action Fund for Fungal Infections, Geneva, Switzerland (D.W. Denning) pathogens. Although China has become the world's second largest economy, it is still a developing country, with millions of impoverished citizens who are susceptible to fungal infections. Fungal keratitis, one of the major causes of avoidable blindness, has been relatively neglected (2). Moreover, old pathogens such as Histoplasma and Talaromyces marneffei (talaromycosis) have expanded $(3,4)$; new hosts contributing to new therapies for malignant and autoimmune disease have increased $(5,6)$; and new patterns, including aspergillosis in pulmonary tuberculosis (PTB) and chronic obstructive pulmonary disease (COPD), are emerging $(7,8)$. In addition, the lack of effective drugs, shortages of well-trained medical care personnel, and unaffordable antifungal drugs result in severe outcomes. Therefore, an estimation of fungal disease burden is needed for China to increase public health awareness and facilitate effective interventions.

As in most other countries, fungal infections are not reportable in China, and the incidence and prevalence are difficult to calculate because of the lack of population-based surveillance data and few high quality epidemiology studies. The Chinese National Fungal Diseases Surveillance System (http://www. chifungi.cn) was established on May 18, 2019, but no data have been released yet. Even with this dearth of data, we have attempted to estimate the burden of fungal disease in China.

\section{Materials and Methods}

\section{Study Procedures}

We conducted a literature review for published epidemiology papers that discussed fungal infections in China. If no epidemiological data existed for a particular fungal disease, we estimated the burden based on fungal infection incidence or prevalence and the specific populations at risk (Figure 1; Appendix Table 1, https://wwwnc.cdc.gov/EID/article/26/9/20-0016App1.pdf). 


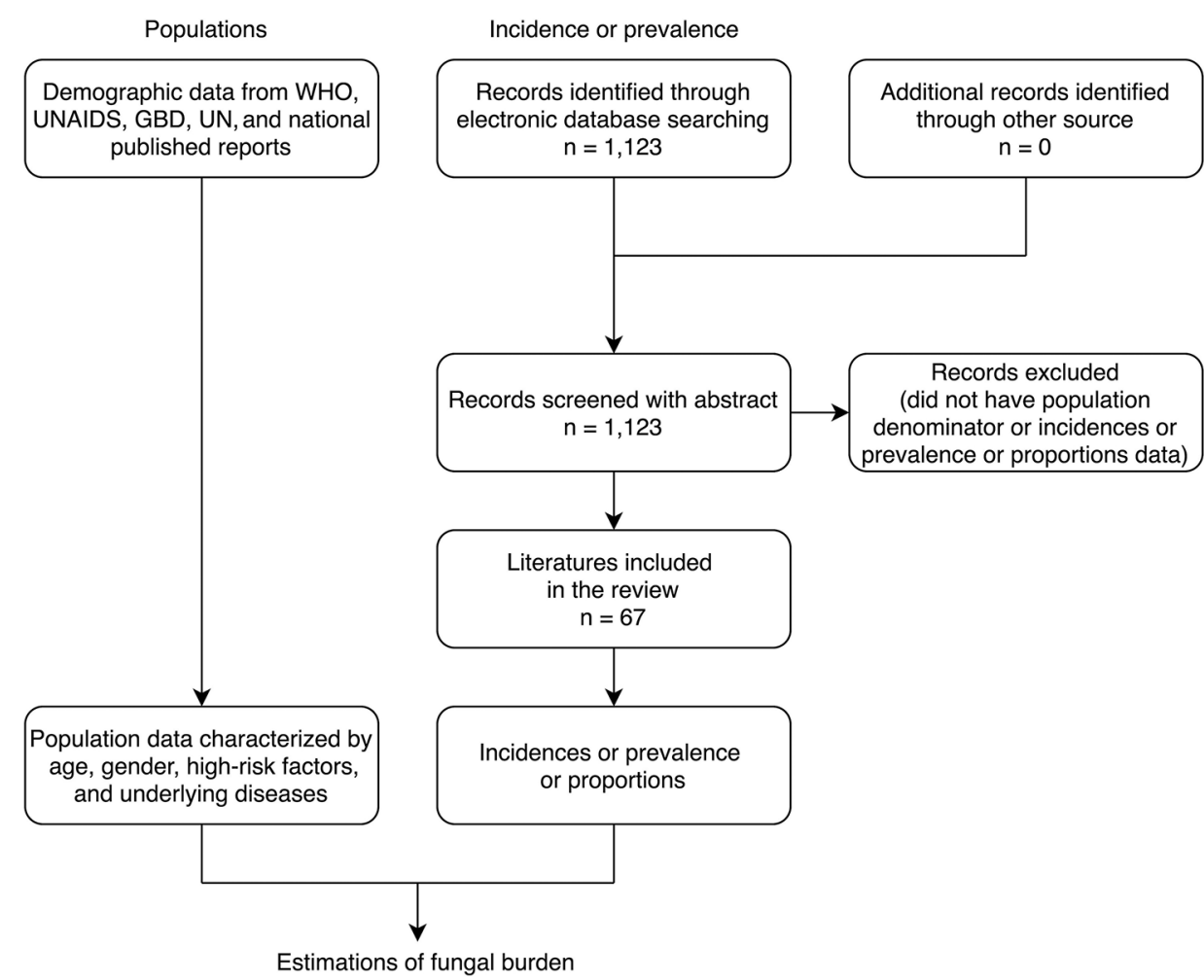

Figure 1. Flowchart of literature review for the human fungal disease burden in China. Reports published in English during January 1950-October 2019 were searched. GBD, Global Burden of Disease, Injuries, and Risk Factors Study; UNAIDS, the Joint Nations Program on HIVIAIDS; UN, United Nations Population Division; WHO, World Health Organization.

\section{High-Risk Population Data}

We obtained population statistics, including China's total, child, and female populations 14-49 years of age, from the United Nations Population Division (9). We derived data on HIV/AIDS in China from the Joint Nations Program on HIV / AIDS (UNAIDS) (10); we used the same source to calculate the proportion of HIV patients on antiretroviral therapy (ART). We consulted the World Health Organization (WHO) tuberculosis report to obtain data on tuberculosis patients; we assumed that $5.6 \%$ of these patients died (11). The numbers of lung cancer and hematological malignancy cases were derived from Global Cancer Observatory (GLOBOCAN) reports (5); data related to transplant recipients were derived from China Organ Transplantation Registration System (COTR) (12). For other high-risk populations, we extracted data from relevant published reports (Table 1).

\section{Selection of Studies for Incidence or Prevalence Data}

We conducted a systematic literature review and identified published epidemiology papers. We searched Web of Science, PubMed, and Embase databases for all the eligible studies published during January 1, 1950-October 7, 2019. Studies selected for this analysis were published in English; we included population-based incidence studies, population-based surveillance systems, and national investigation data. If no available incidence or prevalence data from China were found, we considered published global or international data. All search strings are listed in Appendix Table 2 and studies contributing to estimates for each fungal disease are listed in Appendix Table 3. All the assumptions and calculations for different fungal diseases are detailed in Table 2.

\section{Analysis of Data}

\section{Candidiasis Burden Estimations}

We estimated burdens of invasive candidiasis, Candida peritonitis, Candida peritonitis as a complication of chronic ambulatory peritoneal dialysis (CAPD), and recurrent vulvovaginal candidiasis (RVVC). To estimate invasive candidiasis, we first assessed candidemia incidence in intensive care units (ICUs). Because $\approx 20 \%$ of candidemia episodes in Asia occur in ICUs (19), we used these data to estimate annual incidence for all units. We then estimated Candida peritonitis by assuming that there were 2 episodes of candidemia per episode of intraabdominal candidiasis in the ICU, based on a large prospective study (20). In addition, we estimated Candida peritonitis in CAPD using data from the First Affiliated Teaching Hospital in Tianjin (21). For RVVC, when 
Table 1. Population characteristics in China, by age, gender, high-risk factors, and underlying diseases*

\begin{tabular}{|c|c|c|}
\hline Population characteristic & No., in thousands & Reference \\
\hline Total population & $1,433,784$ & UN, 2019 (9) \\
\hline Population of children 0-14 y & 254,930 & UN, 2020 (9) \\
\hline Female population, $15-49$ y & 403,377 & UN, 2020 (9) \\
\hline Population $>40$ y & 688,074 & UN, $2020(9)$ \\
\hline People living with HIV & 810 & UNAIDS, $2017(10)$ \\
\hline Proportion of HIV patients on ART & $40 \%$ & UNAIDS, $2017(10)$ \\
\hline Adults living with HIV and CD4 $<200$ cells $/ \mu \mathrm{L}$ & 106 & Assumes a 5-y decline in immunity \\
\hline AIDS related deaths & 26 & UNAIDS, $2017(10)$ \\
\hline Annual cases of TB & 856 & WHO $2017(11)$ \\
\hline Annual cases of pulmonary TB who survive & 844 & WHO 2017 (11) \\
\hline Adults with asthma (4.2\%) population & 49,512 & Huang, 2019 (13) \\
\hline Adults with COPD ( $7.2 \%$ of population) & 102,377 & Zhu, 2018 (14) \\
\hline Adults with COPD admitted to hospital each year $(20.1 \%)$ & 29,382 & Zhu, 2018 (14) \\
\hline Lung cancer & 774.3 & GLOBOCAN, 2018 (1) \\
\hline Liver transplants per year & 4.73 & COTR (12) \\
\hline Renal transplants per year & 10.8 & COTR (12) \\
\hline Lung transplants per year & 0.3 & COTR (12) \\
\hline Heart transplants per year & 0.56 & COTR (12) \\
\hline Allogeneic stem cell transplants per year & 5.0 & $\mathrm{Xu}, 2016(15)$ \\
\hline Acute myelogenous leukemia & 41.2 & $\begin{array}{l}40 \% \text { of GLOBOCAN leukemia and multiple } \\
\text { myeloma total, } 2018 \text { (1) }\end{array}$ \\
\hline No. patients on peritoneal dialysis & 73.9 & Wilkie and Davies, 2017 (16) \\
\hline Intensive care unit beds & 86.0 & Murthy, 2012 (17) \\
\hline Intensive care admissions surviving $>24 \mathrm{~h}$ & 5,126 & Du, $2013(18)$ \\
\hline
\end{tabular}

prevalence data were not available, we used the rate of women with RVVC from a recent global estimate (22). We assumed that esophageal candidiasis occurred in $20 \%$ of patients with HIV who were not on ART and 5\% of those taking ART annually (23). Oral candidiasis was estimated only in patients with HIV; we assumed that it occurs in $45 \%$ of patients with AIDS annually (24).

\section{Aspergillosis Burden Estimations}

We calculated burdens of invasive aspergillosis (IA), chronic pulmonary aspergillosis (CPA), allergic bronchopulmonary aspergillosis (ABPA), and severe asthma with fungal sensitization (SAFS). We estimated the annual incidence of IA in hematological malignancy, solid and hematopoietic stem cell transplant (HSCT) recipients, lung cancer, COPD, and deaths from AIDS. We estimated that acute myeloid leukemia accounted for $40 \%$ of the annual incidence of all leukemias and multiple myeloma in 2018 (5). We took the rate of IA of 13\% in hematological malignancy from a study from Taiwan (25), where mold-active prophylaxis was not given, and an equal number of cases were seen in all other leukemia and lymphoma cases. Among allogeneic HSCT recipients, we assumed an IA rate of $10 \%$ and rates in solid organ transplant recipients of $2 \%$ (renal), $6 \%$ (heart), $4 \%$ (liver), and 20\% (lung) (23). For patients with lung cancer, we used a rate of $2.6 \%$ from a large study from China (26).
To estimate the annual incidence of IA in patients with COPD, we used a recent study in Guangzhou Province, which found that the rate of IA in hospitalized patients with COPD was 3.9\% (27). The annual hospitalization rate was a mean of $20.9 \%$, and the number of patients with COPD came from a systematic review (28), from which we estimated the hospitalized patients with COPD. Although this information was not reported from China, we assumed a $4 \%$ autopsy incidence of IA in patients with AIDS (29).

We used the WHO 2017 figures for PTB to calculate CPA (11). We calculated CPA incidence after PTB based on our previous estimate, assuming that $22 \%$ of patients are left with a pulmonary cavity and that $22 \%$ of these patients develop CPA each year, as did $2 \%$ of those without a cavity (30). This calculation derives an annual incidence of CPA, which we converted to a 5 -year period prevalence by assuming a $15 \%$ annual death or surgical resection rate. Given that PTB is one of several underlying causes of CPA, we conservatively assumed that PTB was primarily responsible for $33 \%$ of all CPA cases (31).

The reported rate of asthma in adults in China has increased from $1.42 \%$ in 2012 to $4.2 \%$ in 2019 (13). Ma et al. ascertained that $2.5 \%$ of these patients had ABPA (in secondary care) (32). Severe asthma proportion of adult asthmatics was estimated at $10 \%$, as in other country estimates (23). We used a conservative fungal sensitization rate of 33\% (as in other countries) to estimate the number of SAFS (23). No estimation 
was made about cystic fibrosis in China because few patients currently survive to adulthood.

\section{HIV-Related Infection Burden Estimation}

We estimated burdens of cryptococcal meningitis (CM), Pneumocystis pneumonia (PCP), talaromycosis, and histoplasmosis. We ignored other HIV-related infections because of the lack of population-based data. We derived data for patients with AIDS from those who had a 5 -year decline in CD4 counts to $<200$ cells/ $\mathrm{mL}$ in the total population of HIV patients. We estimated the annual incidence of $\mathrm{CM}$ at $8 \%$ in patients with AIDS (CD4 count

\begin{tabular}{|c|c|c|}
\hline Fungal diseases $\dagger$ & Assumptions & Calculations \\
\hline Candidemia & $\begin{array}{l}\text { 1. Candidemia episodes in ICU }=(I C U \text { beds } \times 365 / \text { median } \\
\text { length of ICU stay }) \times \text { (rate of candidemia in ICU } 1,000 \\
\text { admissions }) \\
\text { 2. } 20 \% \text { of candidemia episodes in Asia occur in ICU }\end{array}$ & Candidemia = Candidemia episodes in ICU/0.20 \\
\hline Candida peritonitis & $\begin{array}{l}\text { Rate of Candida peritonitis is } 50 \% \text { of cases of candidemia } \\
\text { in ICU }\end{array}$ & Candida peritonitis $=$ candidemia in ICU $\times 50 \%$ \\
\hline $\begin{array}{l}\text { Candida peritonitis } \\
\text { CAPD }\end{array}$ & $\begin{array}{l}\text { 1. } 3.7 \% \text { were Candida peritonitis in all episodes of infection } \\
\text { 2. Overall infection incidence was } 0.27 \text { episodes/patient/ } \\
\text { year }\end{array}$ & $\begin{array}{l}\text { Candida peritonitis CAPD }=\text { peritoneal dialysis } \times \\
0.27 \times 3.7 \%\end{array}$ \\
\hline Oral candidiasis & Assumed to occur in $45 \%$ of AIDS cases annually & Oral candidiasis $=$ AIDS $\times 45 \%$ \\
\hline $\begin{array}{l}\text { Esophageal } \\
\text { candidiasis }\end{array}$ & $\begin{array}{l}\text { Assumed to occur in } 20 \% \text { of HIV patients not on ART and } \\
5 \% \text { of patients taking ART annually }\end{array}$ & $\begin{array}{l}\text { Esophageal candidiasis }=(0.2 \times \text { HIV patients not } \\
\text { on ART })+(0.05 \times \text { HIV patients on ART })\end{array}$ \\
\hline RVVC & $\begin{array}{l}\text { Assumed to occur in } 7.2 \% \text { of the female population } 15-49 \\
\text { years of age }\end{array}$ & $\mathrm{RVVC}=($ female population 15-49) $\times 7.2 \%$ \\
\hline IA & $\begin{array}{l}\text { 1. In hematologic malignancy, annual incidence of all } \\
\text { leukemias and multiple myeloma } \times 40 \% \times 13 \% \\
\text { a. Acute myeloid leukemia estimated at } 40 \% \text { of annual } \\
\text { incidence of leukemias and multiple myeloma } \\
\text { b. } 13 \% \text { of patients with acute myeloid leukemia } \\
\text { developed IA } \\
2 \text {. IA in solid and HSCT recipients: assumed } 10 \% \text { in a- } \\
\text { HSCT recipients, } 2 \% \text { of renal transplants, } 6 \% \text { of heart } \\
\text { transplants, } 4 \% \text { of liver transplants, } 20 \% \text { of lung transplants } \\
3 \text {. IA in } 2.6 \% \text { of patients with lung cancer } \\
\text { 4. IA in COPD: COPD patients } \times 20.9 \% \times 3.9 \% \\
\text { a. Annual hospitalization rate for COPD }=20.9 \% \\
\text { b. } 3.9 \% \text { of hospitalized COPD patients developed IA } \\
5 \text {. IA in } 4 \% \text { of HIVIAIDS patients }\end{array}$ & $\begin{array}{l}\text { IA = IA in hematologic malignancy + IA in solid } \\
\text { and HSCT recipients + IA in lung cancer patients } \\
+ \text { IA in COPD patients + IA in HIVIAIDS patients }\end{array}$ \\
\hline CPA & $\begin{array}{l}\text { 1. TB-related CPA: assuming rate of } 22 \% \text { among patients } \\
\text { with lung cavities, } 2 \% \text { of patients without cavities } \\
2.22 \% \text { of patients with pulmonary TB have residual lung } \\
\text { cavities } \\
\text { 3. One third of underlying diseases of CPA are TB }\end{array}$ & Total CPA $=$ TB-related CPA $\times 3$ \\
\hline ABPA & $\begin{array}{l}\text { 1. } 4.2 \% \text { of adults in China have asthma } \\
\text { 2. } 2.5 \% \text { of adults with asthma have ABPA }\end{array}$ & ABPA $=$ adults with asthma $\times 2.5 \%$ \\
\hline SAFS & $\begin{array}{l}\text { 1. Assume a conservative } 33 \% \text { rate of fungal sensitization } \\
\text { in patients with severe asthma } \\
\text { 2. } 10 \% \text { of adults with asthma have severe asthma }\end{array}$ & SAFS $=$ adult population $\times 33 \% \times 10 \%$ \\
\hline $\mathrm{CM}$ & $\begin{array}{l}\text { 1. } 7.1 \% \text { of patients with HIVIAIDS } \\
\text { 2. HIV-related CM is } 21 \% \text { of total CM } \\
\text { 3. Annual incidence of } 0.43 / 100,000 \text { in children }\end{array}$ & $\begin{array}{l}\mathrm{CM}=(7.1 \% \times \mathrm{HIV} / \mathrm{AIDS} \text { patients } / 21 \%)+ \\
0.43 / 100,000 \times \text { child population }\end{array}$ \\
\hline PCP & $\begin{array}{l}\text { 1. } 22.4 \% \text { of HIV-positive patients during a } 2 y \text { period } \\
\text { 2. HIV-related PCP is } 70.22 \% \text { of total } \mathrm{PCP}\end{array}$ & PCP $=22.4 \% \times$ HIVIAIDS patients $/ 2 / 70.22 \%$ \\
\hline Talaromycosis & $\begin{array}{l}\text { Assume } 20 \% \text { of AIDS patients geographically exposed, } \\
\text { attack rate } 15 \%\end{array}$ & Talaromycosis $=$ HIVIAIDS patients $\times 20 \% \times 15 \%$ \\
\hline Histoplasmosis & $\begin{array}{l}\text { Assume } 67 \% \text { of AIDS patients geographically exposed, } \\
\text { attack rate } 5 \%\end{array}$ & Histoplasmosis $=$ HIVIAIDS patients $\times 5 \% \times 67 \%$ \\
\hline Mucormycosis & Assume prevalence is $0.2 / 100,000$ in total population & Mucormycosis $=$ total population $\times 0.2 / 100,000$ \\
\hline Fungal keratitis & $0.007 \%$ of total population & Fungal keratitis $=$ total population $\times 0.007 \%$ \\
\hline Onychomycosis & $2.6 \%$ of total population & Onychomycosis $=$ total population $\times 2.6 \%$ \\
\hline
\end{tabular}


$<200$ cells/mL) (33) and estimated the overall CM annual incidence based on the assumption that the proportion of HIV-positive patients with CM was $21 \%$ (34). In children, 23 cases of CM were diagnosed over a 5-year period (2007-2012) in Shijiazhuang, giving an annual incidence of $0.43 / 100,000$ (35). We conservatively estimated the 2-year incidence of PCP at $22 \%$ of patients with AIDS (36), which comprises 70\% of total cases (37). Only $20 \%$ of the HIV population was assumed to be geographically at risk for infection with T. marneffei; the attack rate was $15 \%$ in patients with AIDS (3). Disseminated histoplasmosis was assumed to occur in $5 \%$ of the geographically exposed population (estimated at 67\%) of patients with AIDS (4).

\section{Mucormycosis, Fungal Keratitis, and Onychomycosis Burden Estimation}

Mucormycosis is a rare fungal infection; the prevalence rate is $0.2-140.0 / 1$ million population (38). We used a global prevalence rate $(2.0 / 1$ million population) to estimate the burden. To estimate the burden of fungal keratitis, which is usually caused by Fusarium spp. and Aspergillus spp. in China, we used the overall prevalence of $0.007 \%$ according to a multicenter study (2). We used the global prevalence rate $(2.6 \%)$ from 11 population-based studies to estimate the onychomycosis burden (39).

\section{Epidemiology Maps}

For talaromycosis and histoplasmosis, which showed new endemic trends, we prepared epidemiology maps according to the number of reported cases in China. We searched the PubMed database for articles published in China during January 1, 1950-October 7, 2019. Reports published in English were included. Search strings and references contributing to the talaromycosis map are listed in Appendix Table 4, and those contributing to the histoplasmosis map are listed in Appendix Table 5.

\section{Prediction of HIV-Related Invasive Fungal Burden}

We made a simple prediction model to estimate the HIV-related fungal burden by 2050 . We derived the prediction data for total population in the next 50 years from UN data (40), and we collected data on HIV and AIDS cases during 2012-2017 to make a linear regression model to predict the number of HIV cases in 2050. If early testing and ART are at the current level, we estimate that $20.4 \%$ of HIV patients will develop advanced HIV disease over time (10). Based on our assumptions, we also predicted the burdens of invasive fungal diseases, including CM, PCP, and talaromycosis.

\section{Results}

\section{Population Profiles}

According to the UN data, the population of China was $\approx 1.4$ billion in 2019 , of whom $18 \%$ were children; 688 million adults were $>40$ years of age, of whom 403 million were women 15-49 years of age (9). The current total number of reported HIV infections in China is 810,000 , and there were 26,000 AIDS-related deaths in 2017. Thus, 784,000 persons were living with HIV in China in 2019, of whom $60 \%$ were not receiving ART and 165,018 had AIDS (CD4 <200) (10). The detailed population characteristics and high-risk populations are described in Table 1.

\section{Candidiasis Burden}

The overall fungal burden in China, according to major risk factors, is summarized in Table 3. In 2012, there were an estimated 86,027 intensive care beds, in China and the rate of candidemia in ICU was documented at 3.2/1000 ICU admissions. The median length of stay in the ICU in China is 6.1 days. Thus, there are 16,402 candidemia episodes in the ICU, and we estimated a total of 82,011 episodes of candidemia per year in all units. Although $C$. albicans remains the most common species associated with candidiasis in ICU patients, other non-albicans Candida (NAC) is becoming increasingly common, and patients with NAC usually have longer antifungal therapy, longer ICU or hospital stay, and slightly higher death rates (41).

We also estimated 8,201 cases of postsurgical Candida peritonitis (intraabdominal candidiasis) by making the assumption that the rate of Candida peritonitis is $50 \%$ of cases of candidemia in the ICU. Given that there were 73,871 patients on CAPD in China in 2017, we estimated 738 peritonitis cases by using the Candida peritonitis episode rate of 0.01 / patient-year.

Except for cutaneous disease, recurrent Candida vaginitis is the most common fungal disease, with aspergillosis, including IA, CPA, ABPA, and SAFS, next (Figure 2). We used the base case of RVVC prevalence in adult premenopausal women (15-49 years of age) previously published: 29,082,000 (range 21,812,000$36,353,000)$ affected women (22). In addition, 74,258 cases of oral candidiasis and 49,240 cases of esophageal candidiasis were expected annually in patients with HIV.

\section{Aspergillosis Burden}

We obtained an estimate of $1,178,747$ cases of IA (82.1/100,000 population). We estimated 32,840 cases in immunocompromised patients and those 
Table 3. Summary of fungal infection burden in China according to major risk factors*

\begin{tabular}{|c|c|c|c|c|c|c|c|}
\hline \multirow[b]{2}{*}{ Infection } & \multicolumn{5}{|c|}{ No. infections per underlying disorder per year } & \multirow{2}{*}{$\begin{array}{l}\text { Total no. } \\
\text { cases }\end{array}$} & \multirow{2}{*}{$\begin{array}{c}\text { Rate/100,000 } \\
\text { population }\end{array}$} \\
\hline & None & HIVIAIDS & Respiratory & Cancer & ICU & & \\
\hline Candidemia & NE & NE & NE & 65,609 & 16,402 & 82,011 & 5.72 \\
\hline \multicolumn{8}{|l|}{ Candida peritonitis } \\
\hline ICU + surgery & NE & NE & NE & NE & 8,939 & 8,939 & 0.62 \\
\hline CAPD & 738 & NE & NE & NE & NE & 738 & 0.05 \\
\hline Oral candidiasis & $\mathrm{NE}$ & 74,258 & NE & NE & NE & 74,258 & 5.18 \\
\hline Esophageal candidiasis & NE & 49,204 & NE & NE & NE & 49,204 & 3.43 \\
\hline Recurrent Candida vaginitis & $29,082,000$ & NE & NE & NE & NE & $29,082,000$ & $4,056.68 \dagger$ \\
\hline IA & NE & 1,040 & $1,145,908$ & 31,800 & NE & $1,178,748$ & 82.21 \\
\hline CPA & NE & NE & 488,716 & NE & NE & 488,716 & 34.09 \\
\hline ABPA & NE & NE & $1,237,797$ & NE & NE & $1,237,797$ & 86.33 \\
\hline SAFS & NE & NE & $1,633,892$ & NE & NE & $1,633,892$ & 113.96 \\
\hline $\mathrm{CM}$ & 26,249 & 13,086 & NE & 26,172 & NE & 65,607 & 4.57 \\
\hline PCP & NE & 18,482 & NE & 9,241 & NE & 27,723 & 1.93 \\
\hline Talaromycosis & NE & 4,951 & NE & NE & NE & 4,951 & 0.35 \\
\hline Mucormycosis & 2,868 & NE & NE & NE & NE & 2,868 & 0.20 \\
\hline Fungal keratitis & 100,365 & NE & NE & NE & NE & 100,365 & 7.00 \\
\hline Onychomycosis & $37,278,384$ & $\mathrm{NE}$ & NE & NE & NE & $37,278,384$ & $2,600.00$ \\
\hline Total burden & $66,490,604$ & 161,021 & $4,506,313$ & 132,822 & 25,341 & $71,316,101$ & $7,002.32$ \\
\hline \multicolumn{8}{|c|}{$\begin{array}{l}{ }^{*} \text { ABPA, allergic bronchopulmonary aspergillosis; ART, antiretroviral therapy; CAPD, continuous ambulatory peritoneal dialysis; CM, cryptococcal } \\
\text { meningitis; CPA, chronic pulmonary aspergillosis; IA, invasive aspergillosis; ICU, intensive care unit; NE, no estimation could be made because of the lack } \\
\text { of data; PCP, pneumocystis pneumonia; SAFS, severe asthma with fungal sensitization. } \\
\text { †Female population only. }\end{array}$} \\
\hline
\end{tabular}

with cancer; of these, 20,000 were in patients with lung cancer and 1,040 in patients with AIDS. The remainder of IA cases in this immunocompromised group were in patients with hematologic malignancies, lymphoma, and transplants. We also calculated $1,145,908$ IA cases derived from COPD.

In China, there were 844,500 survivors of tuberculosis in 2017 (11). We expect an annual incidence of 51,683 cases of tuberculosis-related CPA, and we estimated a 5-year period prevalence of 162,905 cases. Because tuberculosis probably comprises only one third of underlying $\mathrm{CPA}$, the total period prevalence estimate is 488,716 cases (34/100,000 population).

Nearly 50 million adults with asthma live in China; of these, $10 \%$ have severe asthma. Regarding ABPA, the assumption is that $2.5 \%$ of adult asthmatics are affected, leading to a prevalence of $1,237,797$ cases. Among patients with severe asthma, we estimate that 1.6 million have SAFS.

\section{Burdens of HIV-Related Infections}

$\mathrm{CM}$ occurs mainly in immunocompromised populations other than HIV patients in China, as well as in immunocompetent individuals. We thus obtained an estimate of adult CM: 13,086 in patients with AIDS and 26,172 each in immunocompromised and in immunocompetent persons. For CM in children, we estimated 77 cases annually, with an annual incidence of $0.43 / 100,000$ population. We calculated a total of 65,507 CM cases.

We estimated the number of patients with PCP in China as 27,723 (18,482 with HIV and 9,241 with other immunocompromised conditions). This estimate implies an annual incidence of 1.93/100,000 population.

We estimated 4,951 talaromycosis cases in patients with AIDS in southern China. From the literature review, we identified 3,163 cases from 12 different provinces. The provinces with the highest prevalence are Guangxi and Guangdong, which each reported $>1,000$ cases (Figure 3, panel A). Both provinces are located in Pearl River Basin, possibly indicating an endemic trend.

We identified 380 histoplasmosis cases in China from the literature review (Figure 3, panel B). Most of the cases were reported in the region where the Yangtze River flows, also suggesting a new endemic pattern in China. Disseminated histoplasmosis in patients with AIDS was assumed to affect 5,528 persons annually, but we were unable to estimate the burden in non-HIVinfected persons or the burden of chronic pulmonary histoplasmosis. For the prediction of HIV-related invasive fungal burden by 2050, using annual data from 2012-2017 and extrapolating with our estimates, we expect 86,303 cases of $P C P, 61,105$ cases of $C M$, and 23,117 cases of T. marneffei infection (Figure 4).

\section{Mucormycosis, Fungal Keratitis, and Onychomycosis Burden}

We estimated mucormycosis using the global prevalence rate and calculated 2,868 cases. We estimated fungal keratitis based on the total population and estimated 100,365 cases of fungal keratitis annually in China. We estimated 37,278,384 cases of onychomycosis using the global data. 


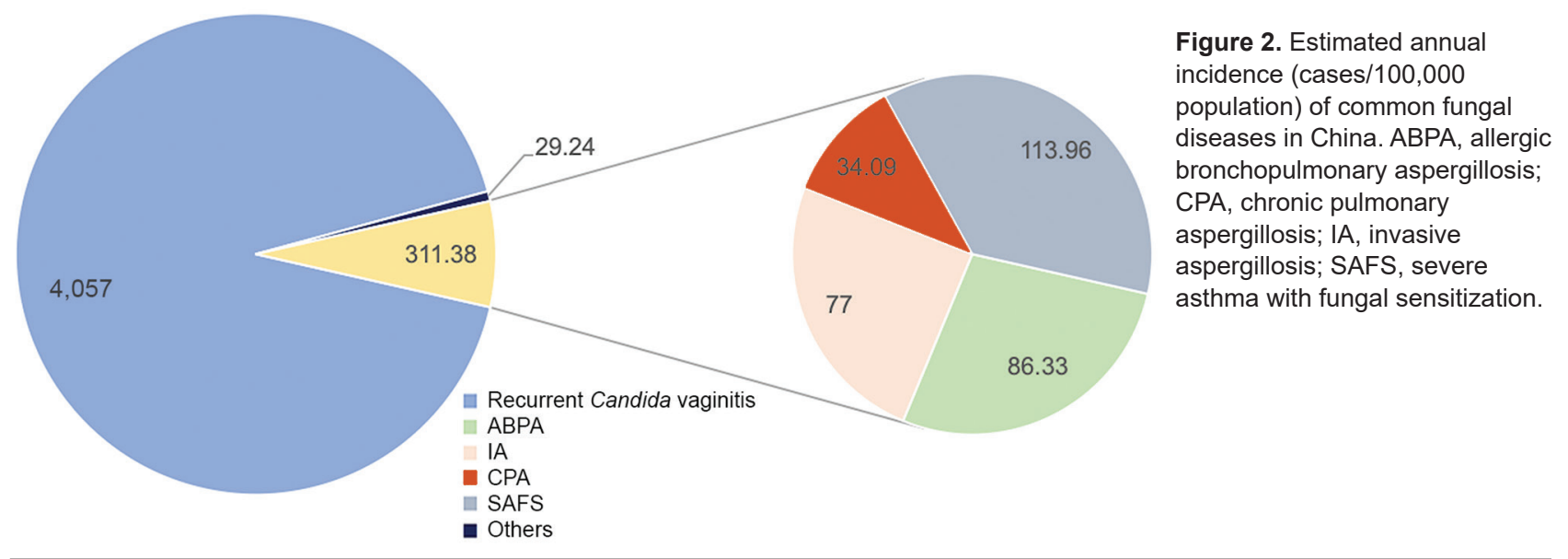

\section{Discussion}

In this study, we estimated that 71 million persons suffer from a fungal disease in China. A total of $2.4 \%$ of the population is affected (excluding onychomycosis because it is superficial), similar to results in other reports from Senegal, Brazil, France, Korea and Germany; the prevalence range is $1.6 \%-3.6 \%$ (1). Multiple new host risk factors other than HIV/AIDS or hematologic malignancy, especially COPD, asthma, and lung cancer, are associated with fungal disease. We found that even immunocompetent children and women may develop fungal diseases. Chronic respiratory diseases, notably PTB and COPD, are risk factors for all manifestations of aspergillosis. Old pathogens, including T. marneffei and Histoplasma capsulatum, exhibit new endemic trends; the Pearl River Basin bears the greatest burden for T. marneffei and the Yangtze River for $H$. capsulatum. Our study contributes to the currently limited data on the burden of fungal disease in China and provides a basis for public health and research priorities.

The incidence of candidiasis has increased in recent years (17). Candidemia is probably underestimated, as we have used only ICU data to explore the total burden of all high-risk populations. Considering the wide use of broad-spectrum antimicrobial drugs and the demographic shift with a largely increasing elderly population, we expect infections to be on the rise.

We have estimated the oral and esophageal candidiasis burdens in HIV-positive patients; these are certainly underestimates of these infections, because many of the populations at risk could not be assessed, such as patients with cancer, those taking oral or inhaled corticosteroids, and newborns. Although the proportions of oral or esophageal candidiasis in this kind of population might be small, given the relatively large size compared to the rather small HIV population, these cases could multiply our estimates. In addition, oral and esophageal candidiasis and colonization are associated with mucosal malignancy and particularly associated with high alcohol consumption (42). If the high number of unsuspected cases of esophageal candidiasis based on data from South Korea is also true in China, this association could contribute to the high number of esophageal cancers seen annually in China (307,359 cases) (43), which could further increase the social and economic burden.

IA is usually severe and fatal, unless diagnosed early. Although profoundly immunocompromised patients are at higher risk, the enormous estimate for China is mostly driven by COPD (97\%). Our estimate of IA prevalence in liver transplant recipients of $4 \%$ is higher than the report from China at $1.7 \%$ (44), but that study was based on histology or culture alone, which is much less sensitive than Aspergillus antigen detection. The same applies to renal transplant recipients (45). Other underlying conditions were newly recognized risk factors for IA, such as diabetes mellitus, systemic lupus erythematosus, and postoperative and burn infections related to contaminated air in hospitals; these were not included in our estimation because of the unavailable incidence rate. Nevertheless, the number of IA cases could also be overestimated because Aspergilli are common fungi in the environment, and a positive result from non-aseptic fluid culture does not always represent disease. On the other hand, we have not estimated IA in most medical ICU patients, and not included the potential for IA complicating annual influenza cases or an epidemic.

In contrast to other countries, where $\mathrm{CM}$ is often diagnosed in patients with HIV or immunocompromised patients, in China, a high proportion of cryptococcosis was reported in immunocompetent persons (34). Jiang et al. reported on 159 HIV-negative 
patients with $\mathrm{CM}$, of whom 85 were normal hosts; however, whether these persons were immunocompetent is unknown, because several genetic predisposition factors for $\mathrm{CM}$ have been found in the ethnic Chinese population (46). Most large-scale studies have been conducted in adults; few were dedicated to pediatric populations. Although children account for only $0.9 \%-2.0 \%$ of all cryptococcal cases, the death rate is high, up to $43 \%$ (47). In a 12-year retrospective study in Beijing, 53 pediatric casepatients were encountered, of whom 41 had no underlying conditions (48). However, the denominator was unavailable. Only an annual incidence of 0.43/100,000 HIV-negative children was reported from the Acute Meningitis-Encephalitis Syndrome Surveillance project (35). Because of the lack of surveillance networks in China, additional studies are required, especially for immunocompetent patients.

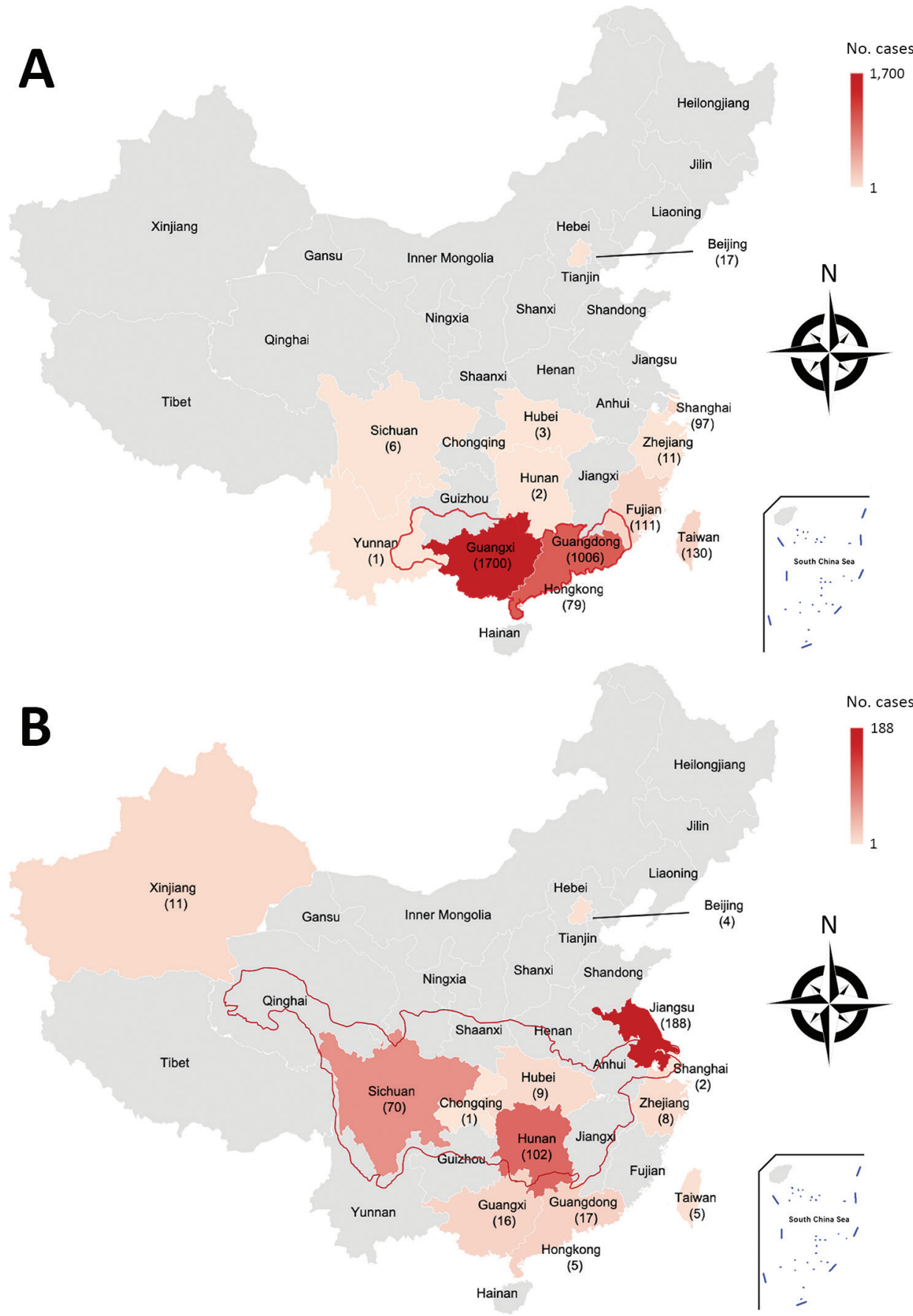

Figure 3. Epidemiology maps for talaromycosis and histoplasmosis, according to the number of reported cases, China. A) Map for talaromycosis. Red border indicates Pearl River basin. B) Map for histoplasmosis. Red border indicates Yangtze River region. Reports published in English during January 1950October 2019 were searched. 


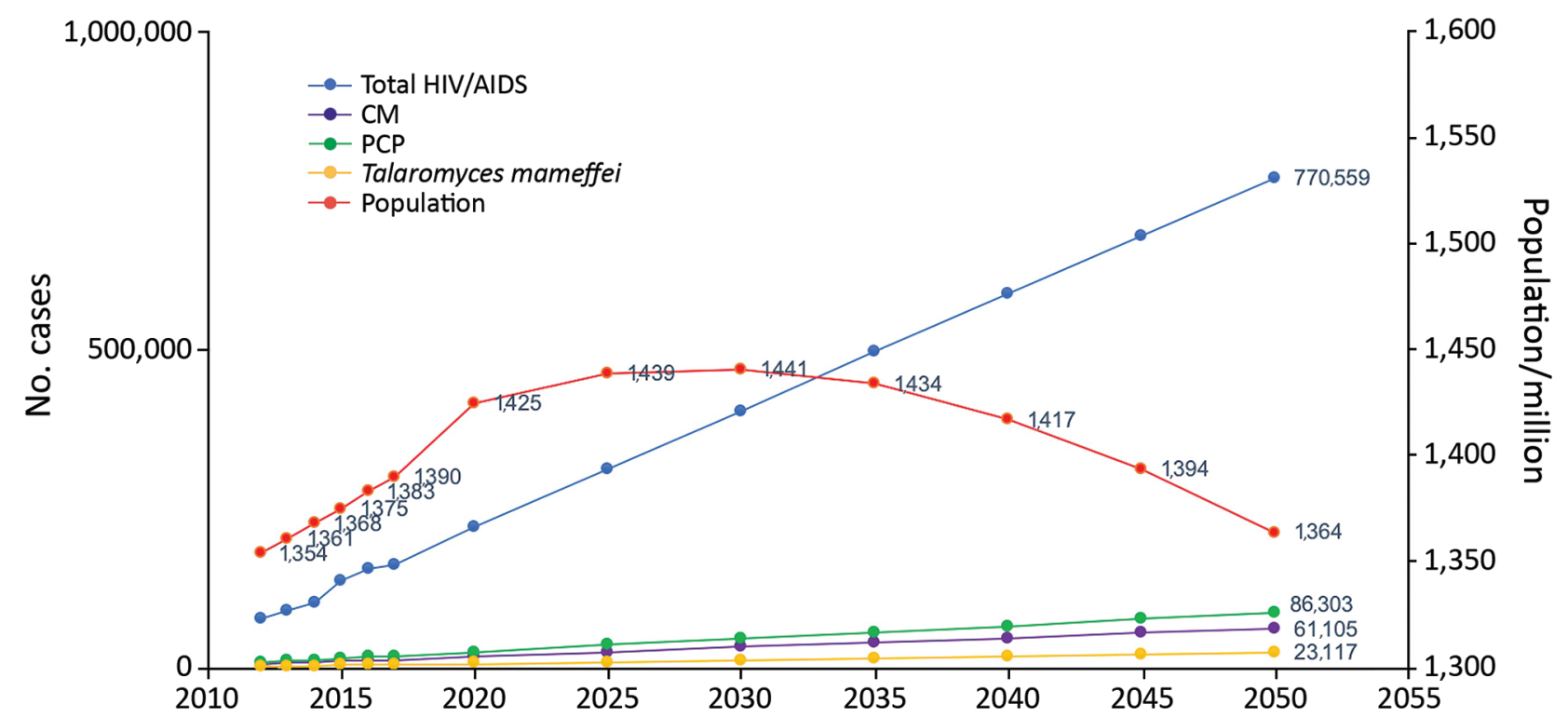

Figure 4. Prediction of HIV-related invasive fungal burden in China by 2050, based on ART and HIV-related disease incidence levels for 2012-2017. ART, antiretroviral therapy; CM, cryptococcal meningitis; PCP, pneumocystis pneumonia.

Although histoplasmosis is a common endemic mycosis in North America, several sporadic cases were reported in China, especially in the Yangtze River region, which was traditionally thought to be nonendemic for Histoplasma capsulatum (3). However, $>300$ histoplasmosis cases have been reported since 1990, and only 17 were identified as imported cases, indicating many authochthonous cases in China (3). T. marneffei infection, the other fatal endemic opportunistic fungal infection disease in Asia, was reported mostly in the southern part of China, possibly linked to an altered microeukaryotic community in subtropical rivers caused by global warming (49). Because this disease was associated mainly with HIV/AIDS, we estimated the incidence only in HIV-positive patients. In addition, given the low national reported statistics of HIV infection (3), the estimation of talaromycosis burden may be far underestimated. More large population-based studies are needed to better clarify the frequency of these fungal infections in these at-risk patients.

The government of China has worked to improve healthcare over the past 2 decades. However, HIV remains a major public health issue, showing the fastest growth among 45 infectious diseases during 2004-2013 with an annual percentage change of $16.3 \%$ (50). Therefore, we made a prediction of HIVrelated opportunistic fungal infections. According to our data, it is likely that CM, PCP, and T. marneffei infection are major health burdens, which call for much more clinical training, financial support, and public policies.
Even though the incidence rate was low compared with those for bacterial and viral infections, our study represents a heavy fungal burden considering the immense population base and high mortality of nonsuperficial mycoses. The drawbacks of our study are the few studies conducted in the country for some infections; the prevalence or incidence are not available for those diseases, including sporotrichosis and some dermatophytosis. Epidemiologic studies are required and population-based surveillance data remain to be estimated, both nationally and regionally. Improved epidemiologic data are necessary for better awareness, better diagnostics, and better therapies.

\section{Acknowledgments}

We thank Xin-Hua Weng for his support and encouragement for the study.

This study was supported by the National Natural Science Foundation of China (grant no. 81971911 and grant no. 8151968 to L.P.Z.) and Major Infectious Diseases Such as AIDS and Viral Hepatitis Prevention and Control Technology Major Projects of China (grant no. 2018ZX10712-001 to R.Y.L.).

\section{About the Author}

Dr. Zhou is a PhD student at Huashan Hospital, Fudan University, Shanghai, China. Her primary research interests are invasive fungal disease diagnosis and treatment. 


\section{References}

1. Global Action Fund for Fungal Infections. Publications: key recent contributions to the academic literature and individual country burdens [cited 2019 Oct 7]. http://www. gaffi.org/media/academic-papers

2. Song X, Xie L, Tan X, Wang Z, Yang Y, Yuan Y, et al. A multi-center, cross-sectional study on the burden of infectious keratitis in China. PLoS One. 2014;9:e113843. https:// doi.org/10.1371/journal.pone.0113843

3. Hu Y, Zhang J, Li X, Yang Y, Zhang Y, Ma J, et al. Penicillium marneffei infection: an emerging disease in mainland China. Mycopathologia. 2013;175:57-67. https://doi.org/10.1007/ s11046-012-9577-0

4. Pan B, Chen M, Pan W, Liao W. Histoplasmosis: a new endemic fungal infection in China? Review and analysis of cases. Mycoses. 2013;56:212-21. https://doi.org/10.1111/ myc.12029

5. The Lancet. GLOBOCAN 2018: counting the toll of cancer. Lancet. 2018;392:985. https:/ / doi.org/10.1016/S0140-6736 (18)32252-9

6. Hung ML, Liao HT, Chen WS, Chen MH, Lai CC, Tsai CY, et al. Invasive aspergillosis in patients with systemic lupus erythematosus: a retrospective study on clinical characteristics and risk factors for mortality. Lupus. 2018;27:1944-52. https://doi.org/10.1177/0961203318796294

7. Chinese State Statistical Bureau. China Statistical Yearbook 2018 [cited 2019 Oct 7]. http:/ / www.stats.gov.cn/tjsj/ ndsj/2018/indexch.htm

8. Wang C, Xu J, Yang L, Xu Y, Zhang X, Bai C, et al.; China Pulmonary Health Study Group. Prevalence and risk factors of chronic obstructive pulmonary disease in China (the China Pulmonary Health [CPH] study): a national cross-sectional study. Lancet. 2018;391:1706-17. https://doi.org/10.1016/S0140-6736(18)30841-9

9. United Nations Population Division. World population prospects 2019 [cited 2019 Oct 7]. https:/ / population. un.org/wpp/Download/Standard/Population

10. UNAIDS. AIDS info: people living with AIDS receiving ART [cited 2019 Oct 7]. http:/ / www.unaids.org/en/ dataanalysis/datatools/aidsinfo

11. World Health Organization. Tuberculosis country profiles [cited 2019 Oct 7]. http://www.who.int/tb/country/data/ profiles/en/index.html

12. Chinese Ministry of Health. China Organ Transplantation Registration System [cited 2019 Oct 7]. http://www.cotr.cn

13. Huang K, Yang T, Xu J, Yang L, Zhao J, Zhang X, et al.; China Pulmonary Health (CPH) Study Group. Prevalence, risk factors, and management of asthma in China: a national cross-sectional study. Lancet. 2019;394:407-18. https:/ / doi.org/10.1016/S0140-6736(19)31147-X

14. Zhu B, Wang Y, Ming J, Chen W, Zhang L. Disease burden of COPD in China: a systematic review. Int J Chron Obstruct Pulmon Dis. 2018;13:1353-64. https://doi.org/10.2147/ COPD.S161555

15. Xu LP, Wu DP, Han MZ, Huang H, Liu QF, Liu DH, et al. A review of hematopoietic cell transplantation in China: data and trends during 2008-2016. Bone Marrow Transplant. 2017;52:1512-8. https://doi.org/10.1038/bmt.2017.59

16. Wilkie $M$, Davies $S$. Insights on peritoneal dialysis in China. Perit Dial Int. 2018;38(Suppl 2):S16-8. https://doi.org/10.3747/pdi.2018.00224

17. Murthy S, Wunsch $\mathrm{H}$. Clinical review: international comparisons in critical care-lessons learned. Crit Care. 2012;16:218. https://doi.org/10.1186/cc11140

18. Du B, An Y, Kang Y, Yu X, Zhao M, Ma X, et al.; China Critical Care Clinical Trial Group. Characteristics of critically ill patients in ICUs in mainland China. Crit Care Med. 2013;41:84-92. https://doi.org/10.1097/ CCM.0b013e31826a4082

19. Tan BH, Chakrabarti A, Li RY, Patel AK, Watcharananan SP, Liu Z, et al.; Asia Fungal Working Group (AFWG). Incidence and species distribution of candidaemia in Asia: a laboratory-based surveillance study. Clin Microbiol Infect. 2015;21:946-53. https:// doi.org/10.1016/j.cmi.2015.06.010

20. Montravers P, Mira J-P, Gangneux J-P, Leroy O, Lortholary $\mathrm{O}$; AmarCand study group. A multicentre study of a ntifungal strategies and outcome of Candida spp. peritonitis in intensive-care units. Clin Microbiol Infect. 2011;17:1061-7. https://doi.org/10.1111/j.1469-0691.2010.03360.x

21. Hu S, Tong R, Bo Y, Ming P, Yang H. Fungal peritonitis dialysis: 5-year review from a North China center. Infection. 2019;47:35-43. https:// doi.org/10.1007/s15010-018-1204-7

22. Denning DW, Kneale M, Sobel JD, Rautemaa-Richardson R. Global burden of recurrent vulvovaginal candidiasis: a systematic review. Lancet Infect Dis. 2018;18:e339-47. https://doi.org/10.1016/S1473-3099(18)30103-8

23. Gamaletsou MN, Drogari-Apiranthitou M, Denning DW, Sipsas NV. An estimate of the burden of serious fungal diseases in Greece. Eur J Clin Microbiol Infect Dis. 2016;35:1115-20. https:// doi.org/10.1007/s10096-016-2642-8

24. Matee MI, Scheutz F, Moshy J. Occurrence of oral lesions in relation to clinical and immunological status among HIVinfected adult Tanzanians. Oral Dis. 2000;6:106-11. https://doi.org/10.1111/j.1601-0825.2000.tb00110.x

25. Chen CY, Sheng WH, Tien FM, Lee PC, Huang SY, Tang JL, et al. Clinical characteristics and treatment outcomes of pulmonary invasive fungal infection among adult patients with hematological malignancy in a medical centre in Taiwan, 2008-2013. J Microbiol Immunol Infect. 2020;53:10614. https:// doi.org/10.1016/j.jmii.2018.01.002

26. Yan X, Li M, Jiang M, Zou LQ, Luo F, Jiang Y. Clinical characteristics of 45 patients with invasive pulmonary aspergillosis: retrospective analysis of 1711 lung cancer cases. Cancer. 2009;115:5018-25. https://doi.org/10.1002/ cncr.24559

27. Xu H, Li L, Huang WJ, Wang LX, Li WF, Yuan WF. Invasive pulmonary aspergillosis in patients with chronic obstructive pulmonary disease: a case control study from China. Clin Microbiol Infect. 2012;18:403-8. https://doi.org/10.1111/ j.1469-0691.2011.03503.x

28. Zhu B, Wang Y, Ming J, Chen W, Zhang L. Disease burden of COPD in China: a systematic review. Int J Chron Obstruct Pulmon Dis. 2018;13:1353-64. https://doi.org/10.2147/ COPD.S161555

29. Khoo S, Denning DW. Invasive aspergillosis in patients with AIDS. Clin Infect Dis. 1994;19(suppl1):S41-8. https:/ / doi.org/ 10.1093/clinids/19.supplement_1.s41

30. Denning DW, Pleuvry A, Cole DC. Global burden of chronic pulmonary aspergillosis as a sequel to pulmonary tuberculosis. Bull World Health Organ. 2011;89:864-72. https:/ / doi.org/10.2471/BLT.11.089441

31. Smith NL, Denning DW. Underlying conditions in chronic pulmonary aspergillosis including simple aspergilloma. Eur Respir J. 2011;37:865-72. https:/ / doi.org/10.1183/ 09031936.00054810

32. Ma YL, Zhang WB, Yu B, Chen YW, Mu S, Cui YL. Prevalence of allergic bronchopulmonary aspergillosis in Chinese patients with bronchial asthma [in Chinese]. Zhonghua Jie He He Hu Xi Za Zhi. 2011;34:909-13.

33. Chen J, Zhang R, Shen Y, Liu L, Qi T, Wang Z, et al. Serum cryptococcal antigen titre as a diagnostic tool and a predictor of mortality in HIV-infected patients with cryptococcal 
meningitis. HIV Med. 2019;20:69-73. https:/ / doi.org/10.1111/ hiv.12679

34. Li Z, Liu Y, Cao H, Huang S, Long M. Epidemiology and clinical characteristics of cryptococcal meningitis in China (1981-2013): a review of the literature. Med Mycol: Open Access. 2017;3:1. https:// doi.org/10.21767/2471-8521.100022

35. Guo J, Zhou J, Zhang S, Zhang X, Li J, Sun Y, et al. A casecontrol study of risk factors for HIV-negative children with cryptococcal meningitis in Shi Jiazhuang, China. BMC Infect Dis. 2012;12:376. https:/ / doi.org/10.1186/1471-2334-12-376

36. Chan CK, Alvarez Bognar F, Wong KH, Leung CC, Tam CM, Chan KC, et al. The epidemiology and clinical manifestations of human immunodeficiency virus-associated tuberculosis in Hong Kong. Hong Kong Med J. 2010;16:192-8.

37. Guo F, Chen Y, Yang SL, Xia H, Li XW, Tong ZH. Pneumocystis pneumonia in HIV-infected and immunocompromised nonHIV infected patients: a retrospective study of two centers in China. PLoS One. 2014;9:e101943. https://doi.org/ 10.1371/ journal.pone.0101943

38. Prakash H, Chakrabarti A. Global epidemiology of mucormycosis. J Fungi (Basel). 2019;5:26. https:/ / doi.org/ 10.3390/jof5010026

39. Sigurgeirsson B, Baran R. The prevalence of onychomycosis in the global population: a literature study. J Eur Acad Dermatol Venereol. 2014;28:1480-91. https:/ / doi. org/10.1111/jdv.12323

40. United Nations Population Division. Demographic components of future population growth [cited 2019 Oct 7]. https://www.un.org/en/development/desa/population/ theme/trends/dem-comp-change.asp

41. Gong X, Luan T, Wu X, Li G, Qiu H, Kang Y, et al. Invasive candidiasis in intensive care units in China: risk factors and prognoses of Candida albicans and non-albicans Candida infections. Am J Infect Control. 2016;44:e59-63. https:/ / doi.org/10.1016/j.ajic.2015.11.028

42. Alnuaimi AD, Wiesenfeld D, O'Brien-Simpson NM, Reynolds EC, McCullough MJ. Oral Candida colonization in oral cancer patients and its relationship with traditional risk factors of oral cancer: a matched case-control study. Oral Oncol. 2015;51:139-45. https:// doi.org/10.1016/ j.oraloncology.2014.11.008
43. Choi JH, Lee CG, Lim YJ, Kang HW, Lim CY, Choi JS. Prevalence and risk factors of esophageal candidiasis in healthy individuals: a single center experience in Korea. Yonsei Med J. 2013;54:160-5. https://doi.org/10.3349/ ymj.2013.54.1.160

44. Yang CH, He XS, Chen J, Ouyang B, Zhu XF, Chen MY, et al. Fungal infection in patients after liver transplantation in years 2003 to 2012. Ann Transplant. 2012;17:59-63. https://doi.org/10.12659/ AOT.883695

45. Zhang XD, Hu XP, Yin H, Wang W, Zhang X, Ma LL, et al. Aspergillus pneumonia in renal transplant recipients. Chin Med J (Engl). 2008;121:791-4. https://doi.org/10.1097/ 00029330-200805010-00007

46. Jiang YK, Wu JQ, Zhao HZ, Wang X, Wang RY, Zhou LH, et al. Genetic influence of Toll-like receptors on non-HIV cryptococcal meningitis: an observational cohort study. EBioMedicine. 2018;37:401-9. https:/ / doi.org/10.1016/ j.ebiom.2018.10.045

47. Gumbo T, Kadzirange G, Mielke J, Gangaidzo IT, Hakim JG. Cryptococcus neoformans meningoencephalitis in African children with acquired immunodeficiency syndrome. Pediatr Infect Dis J. 2002;21:54-6. https:/ / doi. org/ 10.1097/00006454-200201000-00012

48. Liu L, Guo L, Liu Y, Chen T, Li S, Yang Y, et al. Clinical characteristics and prognosis of pediatric cryptococcosis in Beijing Children's Hospital, 2002-2014. Eur J Pediatr. 2017;176:1235-44. https:// doi.org/10.1007/s00431-017-2974-0

49. Chen W, Ren K, Isabwe A, Chen H, Liu M, Yang J. Stochastic processes shape microeukaryotic community assembly in a subtropical river across wet and dry seasons. Microbiome. 2019;7:138. https:/ / doi.org/10.1186/s40168-019-0749-8

50. Yang S, Wu J, Ding C, Cui Y, Zhou Y, Li Y, et al.

Epidemiological features of and changes in incidence of infectious diseases in China in the first decade after the SARS outbreak: an observational trend study. Lancet Infect Dis. 2017; 17:716-25. https://doi.org/10.1016/S1473-3099(17)30227-X

Address for correspondence: Li-Ping Zhu, Department of Infectious Diseases, Huashan Hospital, Fudan University, 12 Central Urumqi Road, Shanghai 200040, China; email: zhulp@fudan.edu.cn 